\title{
Human Resource Staffing and Service Functions of Community Health Services Organizations in China
}

Jun Yang, $M S^{1}$

Aimin Guo, BS

Yadong Wang, MS ${ }^{2}$

Yali Zhao, $M S^{1}$

Xinbua Yang, $M S^{1}$

Hang $\mathrm{Li} \mathrm{PbD}^{1}$

Roger Duckitt, $M D^{3}$

Wannian Liang, $\mathrm{PbD}^{4}$

${ }^{1}$ School of Public Health and Family Medicine, Capital Medical University, Beijing,

China

${ }^{2}$ School of Health Administration and Education, Capital Medical University, Beijing, China

${ }^{3}$ Department of Cardiology, Royal Hampshire County Hospital, Winchester, England

${ }^{4}$ Beijing Municipal Health Bureau, Beijing, China

\begin{abstract}
PURPOSE We report a study on the developmental status of human resource staffing and service functions of community health services (CHS) in China and offer recommendations for improving the CHS in the future.

METHODS A study questionnaire was completed by 712 CHS organizations distributed in 52 cities and districts in all areas of China using a multilevel stratified randomized sampling method. Data were collected on the backgrounds, human resources, and service functions of CHS organizations.
\end{abstract}

RESULTS We found that $68.2 \%$ of doctors and $86.5 \%$ of nurses employed in CHS centers have low-level medical training. The doctor-nurse ratio in CHS centers is 1.2 to 1 and in CHS stations is 1.3 to 1 . More than $50 \%$ of CHS organizations have developed on-the-job training programs, causing cost trends for staff training to increase. Although the delivery of basic clinical services and public health services is steadily increasing, 58.6\% of stations are open less than 12 hours per day. Health records are established in a high proportion of CHS organizations. Two kinds of health education-general public health education, and personal education for specific problems-have been adopted by more than $92 \%$ of $\mathrm{CHS}$ centers and $90 \%$ of $\mathrm{CHS}$ stations.

CONCLUSIONS Desired functions for CHS organizations have been partially achieved. Training for doctors and nurses engaged in CHS should be promoted and improved as quickly as possible. Training in basic clinical services and management of noncommunicable chronic diseases should be strongly promoted. Changes in government policies should be pursued to promote effective support for the development of CHS.

Ann Fam Med 2008;6:421-427. DOI: 10.1370/afm.888.

\section{INTRODUCTION}

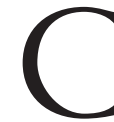

hina is undergoing the most rapid industrialization and urbanization in the history of humankind. As a result, both the level of education and the expectations of the population have increased. The Chinese government is revising its approach to how medicine is practiced within the health care system. At present, one important task is how best to develop community health services (CHS) centers throughout China. To realize this effort, it is necessary to understand the context of China's medical education and health care system.

\section{Conflicts of interest: none reported}

\section{CORRESPONDING AUTHOR}

Wannian Liang, PhD

Beijing Municipal Health Bureau

Beijing 100053, China

mtjyang@ccmu.edu.cn

\section{China's Medical Education System}

In China, medical educational programs include 5- to 8-year post-high school training programs, 3-year post-high school programs, 4-year post-middle school programs, and barefoot doctors. ${ }^{1}$ The 3 -year post-high school programs and 4-year post-middle school programs were copied from the Soviet Union and were adopted by China after the Cultural Revolu- 
tion in 1976. Currently, 5- to 8 -year post-high school training is the most frequently used medical training program. The 3-year post-high school programs are decreasing, and 4-year post-middle school programs have almost disappeared. Because local physicians were in short supply when P. R. China was founded in 1949, the so-called barefoot doctors, who were basically farmers with no proper medical education, usually only 3 to 6 months of basic medical training, took care of the primary health care needs in their communes., 2,3 Today, on-the-job training is being emphasized for the remaining group of barefoot doctors. ${ }^{4}$

\section{China's Medical Professional Titles}

The term pbysician in China refers to medical health care professionals who come from a wide range of educational backgrounds: 5 - to 8 -year post-high school training programs, 3-year post-high school programs, 4-year post-middle school programs, and barefoot doctors. ${ }^{1}$ The 3 levels of professional physician titles-senior, middle, and junior - are based primarily on length of training. A junior doctor from a 5-year post-high school training program usually needs about 5 years of medical practice to move from the junior to the middle level and a total of 15 years to achieve the senior-level professional title. A basic health care clinician with a 3-year post-high school program or 4-year post-middle school program will need much more practical time to reach a higher professional title. Generally, the higher the medical degree achieved, the less practical time will be needed to attain a higher professional title.

\section{China's Medical Care System}

The Chinese government has 2 health care systems, one based on hospital systems and the second based on CHS centers. Hospital systems are developed around tertiary and secondary hospitals in cities and around township hospitals in rural areas. CHS organizations include CHS centers and their affiliated stations.

\section{Chinese Community Health Services}

At present, China faces several major health care problems.

1. The population is aging. In 2005, persons older than 65 years of age accounted for $7.69 \%$ of China's total population. ${ }^{5}$ China, however, has no geriatric subspecialty to manage chronic disorders and comorbid conditions in elderly patients in communities. ${ }^{3}$

2. There is an uneven allocation of health care resources between urban and rural areas. Sixty-two percent of the population of China lives in rural areas, whereas $80 \%$ of the medical institutions are concentrated in cities. In 2005, high-level medical resources tended to be concentrated in large-capacity hospitals. ${ }^{5}$
Only 29\% of Chinese people have health insurance. Out-of-pocket expenses accounted for $58 \%$ of health care spending in China in 2002. ${ }^{2}$

3. The types of diseases are changing. The causes of morbidity and mortality have shifted from acute infectious and communicable diseases to chronic noncommunicable diseases.

4. There is a strained relationship between patients and physicians. Country doctors have limited training, and many peasants seek care directly from specialists at large hospitals. Busy specialists often have insufficient time to communicate adequately with patients. There are 2 major complaints emerging from the Chinese people: they report that it is "expensive health care to receive" and that they have "inconvenient access to health care."

To address these problems, China has drafted new goals and approaches to medical education and the medical care system that are directed toward improving the health of China's huge population. ${ }^{3}$ Family medicine training (ie, general practice) and family physicians (ie, general practitioners) were introduced to China at the end of the 1980s. ${ }^{6}$

Family medicine (general practice) achieved formal status as an academic discipline in medical schools in 1999. ${ }^{3}$ Several education and training programs for family medicine include basic sciences and theory of family medicine in medical schools, on-the-job training programs, continuing education for family doctors, ${ }^{1}$ and residency training programs. Of the many levels of physician training in China, doctors who work in CHS organizations often have 3 or fewer years of professional training and are still widely referred to as family doctors, ie, general practitioners.

China initiated its CHS program in 1997. Since then, the CHS has become an important part of medical care through which continuing and comprehensive health care can be provided. The public health responsibility for promoting good health in all age-groups can be increased in community settings by family doctors (general practice doctors) and their primary care teams. The scope of the CHS organization is described symbolically by the government as " 1 body, 6 aspects." The body is the CHS organization. The 6 aspects consist of basic clinical services, prevention, health education, women and children's care, elderly care, immunizations, and physical rehabilitation. ${ }^{1,3,6}$

$\mathrm{CHS}$ centers and stations have similar functions but have different service populations. A center is in charge of 3 to 6 stations for every 30,000 to 100,000 residents according to the size of a region, and each station provides services to about 10,000 residents. The station reports cases to the CHS center, and the latter collates and reports cases to the local health 
administration department. Both the centers and stations are paid primarily by the government. ${ }^{7}$

By the end of the 2002, 2,406 CHS centers and 9,700 CHS stations had been established in China. ${ }^{2}$

To understand our suggestions for improvement of CHS in China (which we based on our experience), it is necessary to describe the status of human resources and service functions of CHS found by this national survey.

\section{METHODS}

Our survey was conducted by questionnaire interview in August and September of 2003. The questionnaire was made up of a standard set of questions for directors of selected CHS centers, including questions on background information, human resources, and service functions.

\section{Sampling Methods}

Following suggestions from the Ministry of Health of China, about $7 \%$ of CHS organizations, including centers and stations (712) were selected by the multilevel stratified random sampling method (Figure 1).

\section{Training Programs for This Survey}

For the survey 2 training programs were conducted, 1 for trainers and 1 for interviewer training. The trainer

\section{Figure 1. Sampling flow of community health services centers and stations in 2003 in China.}

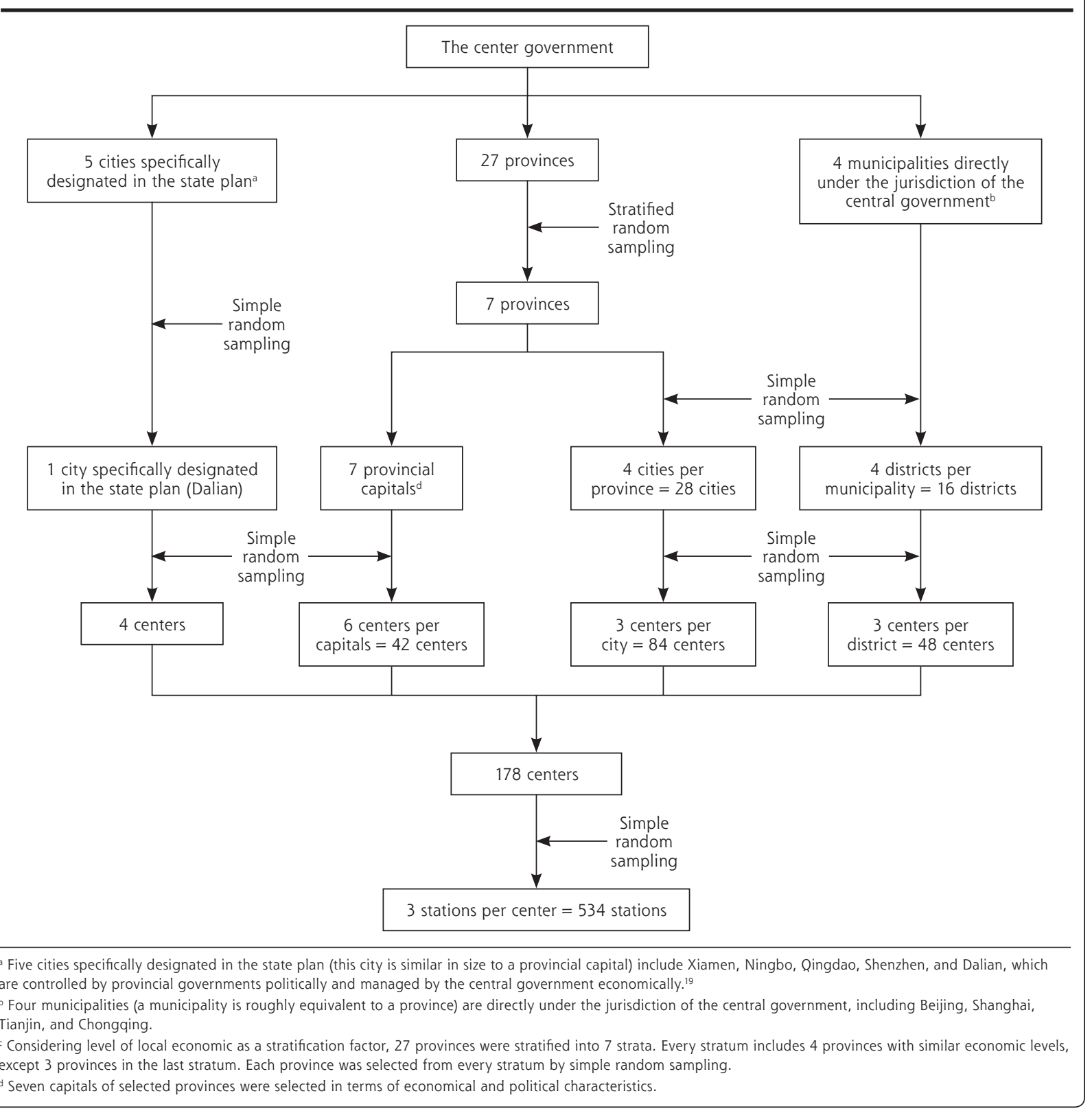


program was conducted by 4 researchers of the Ministry of Health of China in Beijing, in which 12 trainers came from 7 provinces, 4 municipalities, and Dalian. The interviewer-training programs were conducted by 11 trainers in selected provinces; 51 interviewers came from 7 provincial capitals and 28 cities, and 16 districts and municipalities. A standardized training manual and methods were used in the training programs.

Fifty-two interviewers, including 1 trainer from Dalian, conducted interviews with 178 directors from 178 selected CHS centers. Because 534 selected CHS stations are affiliated with the 178 selected CHS centers, both the centers' and stations' questionnaires were answered only by directors of the centers. One hundred seventy-eight interviews were conducted, and the

Table 1. Average Number of Different Staff Positions in CHS Organizations in 2003 in China

\begin{tabular}{lcccc}
\hline \multirow{2}{*}{ Staff Position } & \multicolumn{2}{c}{ Center } & \multicolumn{2}{c}{ Station } \\
\cline { 2 - 5 } Doctor & No. & $\%$ & No. & $\%$ \\
Nurse & 24.0 & 36.8 & 3.5 & 42.7 \\
Pharmacist & 17.0 & 26.1 & 2.3 & 28.0 \\
Laboratory assistant & 5.8 & 8.9 & 0.8 & 9.8 \\
Medical technician & 6.2 & 4.3 & 0.3 & 3.7 \\
Manager & 3.6 & 5.5 & 0.7 & 8.4 \\
Others & 5.8 & 8.9 & 0.3 & 3.7 \\
\hline CHS = community health services. & & & \\
\hline
\end{tabular}

Table 2. Average Designation of Professional Titles in CHS Organizations in 2003 in China

\begin{tabular}{lcccc}
\hline \multirow{2}{*}{$\begin{array}{l}\text { Professional } \\
\text { Status }\end{array}$} & $\begin{array}{c}\text { No. of } \\
\text { Doctors }\end{array}$ & $\%$ & $\begin{array}{c}\text { No. of } \\
\text { Doctors }\end{array}$ & $\%$ \\
\cline { 2 - 5 } Senior-level title & 2.9 & 11.5 & 0.5 & 13.5 \\
Middle-level title & 9.4 & 37.1 & 1.5 & 40.5 \\
Junior-level title & 12.5 & 49.4 & 1.6 & 43.3 \\
No title & 0.5 & 2.0 & 0.1 & 2.7 \\
\hline CHS = community health services. & & & \\
\hline
\end{tabular}

Table 3. Average Number of Doctors and Nurses and Their Medical Educational Background in CHS Organizations in China, 2003

\begin{tabular}{lcccc}
\hline \multirow{2}{*}{$\begin{array}{l}\text { Medical Educational } \\
\text { Background }\end{array}$} & \multicolumn{2}{c}{ Center } & \multicolumn{2}{c}{ Station } \\
\cline { 2 - 5 } & $\begin{array}{c}\text { Doctor } \\
\text { No. (\%) }\end{array}$ & $\begin{array}{c}\text { Nurse } \\
\text { No. (\%) }\end{array}$ & $\begin{array}{c}\text { Doctor } \\
\text { No. (\%) }\end{array}$ & $\begin{array}{c}\text { Nurse } \\
\text { No. (\%) }\end{array}$ \\
\hline $\begin{array}{l}\text { 5-8-year post-high school training } \\
\text { program }\end{array}$ & $6.0(25.4)$ & $0.3(1.8)$ & $0.7(19.4)$ & $0.1(4.0)$ \\
3-year post-high school program & $9.2(39.0)$ & $3.6(21.2)$ & $1.6(44.4)$ & $0.4(16.0)$ \\
4-year post-middle school program & $6.9(29.2)$ & $11.1(65.3)$ & $1.1(30.6)$ & $1.7(68.0)$ \\
No medical educational background & $1.5(6.4)$ & $2.0(11.7)$ & $0.2(5.6)$ & $0.3(12.0)$ \\
\hline CHS = community health services. & & & & \\
\hline
\end{tabular}

completed questionnaires were mailed by 52 interviewers to the Ministry of Health.

\section{Quality Control}

There were 3 steps to develop the questionnaire. Initially question lists were developed by collecting and extracting information from references. The questions were then evaluated by a formal consensus process based on a nominal group technique. Finally, the questionnaire was defined by a pilot survey.

We conducted the pilot survey on 14 directors of CHS organizations from 2 districts of Beijing and Tangshan, and we assessed internal consistency reliability (Cronbach's $\alpha$ ) and reproducibility (over a 1-month period in 14 stable directors) of the questionnaire. The questionnaire was internally consistent (Cronbach $\alpha=.80$ ) and reliable (intraclass correlations $=0.80$ and $0.85)$. Content validity of the questionnaire was also confirmed by epidemiologists and statisticians. The results indicated that the questionnaire has good reliability and validity.

The interview was conducted face to face between interviewers and interviewees. The interviewees were assured that they would remain anonymous during the interview and the analysis. There was a strict review process and supervision by the team to ensure the survey quality. Data were entered twice independently and checked for errors to enhance the accuracy.

\section{Data Analysis}

Descriptive statistical methods were used to analyze the data by using SAS, version 8.01 (SAS Institute Inc, Cary, North Carolina).

\section{RESULTS}

\section{Human Resource Staffing in CHS Organizations of China in 2003}

Comapred with centers, CHS stations do not have a sufficient number of doctors and nurses (Table 1), and they have lower professional titles and less thoroughly trained medical backgrounds and (Tables $2,3)$. The doctor-nurse ratio is about 1.2 to 1 in CHS centers and 1.3 to 1 in stations (Table 1 ).

More than $50 \%$ of CHS organizations have developed the on-the-job training programs. Expenditures for staff training have increased from 2000 to 2002, and the percentages of training costs in the total expenditures of CHS centers and stations are also rising (Table 4). 
Table 4. Average Staff Training Expenditures per CHS Organization, 2000-2002 (USD:RMB = 1:7.7)

\begin{tabular}{lcccc}
\hline & \multicolumn{2}{c}{ Center } & \multicolumn{2}{c}{ Station } \\
\cline { 2 - 5 } Year & $\begin{array}{c}\text { Staff Training } \\
\text { Expense, } \mathbf{\$}\end{array}$ & $\begin{array}{c}\text { Within Total } \\
\text { Expenditure, \% }\end{array}$ & $\begin{array}{c}\text { Staff Training } \\
\text { Expense, } \mathbf{\$}\end{array}$ & $\begin{array}{c}\text { Within Total } \\
\text { Expenditure, \% }\end{array}$ \\
\hline 2000 & 1,364 & 0.26 & 65 & 0.30 \\
2001 & 1,740 & 0.29 & 104 & 0.34 \\
2002 & 2,104 & 0.31 & 156 & 0.37 \\
\hline
\end{tabular}

CHS = community health services. USD:RMB = US dollar:rénmínbi (The exchange rate of the US dollar against the Chinese currency, yuan).

Table 5. Quantity of Some Services Provided by All CHS Organizations From 2000 to 2002 (in Thousands)

\begin{tabular}{lrrr}
\hline Service & $\mathbf{2 0 0 0}$ & $\mathbf{2 0 0 1}$ & $\mathbf{2 0 0 2}$ \\
\hline Outpatient services & 9,247 & 11,091 & 12,680 \\
Family (home) care beds ${ }^{\mathrm{y}}$ & 67 & 66.7 & 128 \\
Home visits & 201 & 229 & 376 \\
Patient discharges from service & 62 & 62.6 & 81 \\
\hline CHS = community health services. & & & \\
a Family (home) care beds are an in home service provided for patients with \\
chronic diseases or terminal illness who cannot travel to a clinic for doctor visits.
\end{tabular}

Table 6. Hours of Service Availability in CHS Organizations in China

\begin{tabular}{lcc}
\hline $\begin{array}{l}\text { Hours Open } \\
\text { Each Day }\end{array}$ & Center No. (\%) & Station No. (\%) \\
\hline$\leq 8$ & $23(11.5)$ & $90(17.8)$ \\
$9-12$ & $33(16.6)$ & $206(40.8)$ \\
$13-24$ & $143(71.9)$ & $209(41.4)$ \\
\hline
\end{tabular}

$\mathrm{CH}=$ community health services.

Table 7. CHS Organizations Providing Different Public Health Services in China in 2003

\begin{tabular}{lcccc}
\hline \multirow{2}{*}{$\begin{array}{l}\text { Public Health } \\
\text { Service }\end{array}$} & \multicolumn{2}{c}{ Centers } & \multicolumn{2}{c}{ Stations } \\
\cline { 2 - 5 } & No. & $\%$ & No. & $\%$ \\
\hline Maternal care & 153 & 77.3 & 223 & 44.3 \\
Child care & 162 & 81.8 & 233 & 47.2 \\
Immunizations & 161 & 80.9 & 246 & 49.0 \\
Health records $^{\mathrm{a}}$ & 171 & 85.5 & 400 & 78.7 \\
\hline
\end{tabular}

$\mathrm{CHS}=$ community health services

a The health record, a useful tool for CHS based on a problem-oriented medical record, is somewhat different from the traditional inpatient and outpatient record, which consists of a personal health record, a family health record, and a community health record.

\section{Service Functions of CHS Organizations of China in 2003}

The basic clinical and public health services provided by CHS organizations have increased from 2000 to 2002 (Table 5). Although the hours of operation approach 24 hours a day in most of the CHS centers, the operating hours of $\mathrm{CHS}$ stations are often insufficient (Table 6). CHS centers provide more public health services than do stations, and the proportion of CHS organizations establishing health records is at a high level (Table 7). The discrepancy between the total number of centers and stations in Tables 6 and 7 and total number in Figure 1 is due to administrative changes between 2002 (the year when the sampling materials were produced) and 2003 (the year when the fieldwork was done); some township-level units were split into 2, each with its own health center.

The number of CHS organizations providing management of noncommunicable chronic diseases increased markedly from 2000 to 2002 (Table 8).

Many methods for health education in CHS have been developed. Most CHS organizations have adopted visual health educational materials, health consultation, and oral education presentations in clinics.

\section{DISCUSSION}

\section{Human Resources in CHS Organizations}

Nurses play an important role in taking care of patients in CHS organizations, especially in the management of noncommunicable chronic disease, family (home) care patients, and home visits. Because CHS stations are usually distributed in residential areas, residents can visit a family (general) doctor conveniently at those stations. There is an obvious need to allocate more doctors and nurses to stations. The central government is using several methods to attract more doctors and nurses with better educational backgrounds to work at CHS organizations and to reach the aim of a doctor-nurse ratio of 1 to 1 or more, ${ }^{7}$ including service lists for CHS organizations, raising salaries for medical staffs based on finished tasks, and providing more opportunities to participate in continuing medical education programs and academic conferences.

When CHS was first developed, the Chinese government provided more support for comprehensive hospitals than for CHS organizations. The result was a huge disparity between the 2 systems in salary and opportunities for promotion. Many doctors and nurses with better educational backgrounds or higher professional titles preferred to work at hospitals. Patients naturally elected to see doctors in hospitals because of their higher prestige and perceived levels of training. ${ }^{8}$

The Chinese government implemented several programs since 2000 to improve the competency of 


\begin{tabular}{|c|c|c|c|c|c|c|}
\hline \multirow{2}{*}{$\begin{array}{l}\text { Type of } \\
\text { Chronic Disease }\end{array}$} & \multicolumn{2}{|c|}{2000} & \multicolumn{2}{|c|}{2001} & \multicolumn{2}{|c|}{2002} \\
\hline & Center & Station & Center & Station & Center & Station \\
\hline Hypertension & 81 & 197 & 112 & 265 & 159 & 395 \\
\hline Diabetes & 74 & 189 & 105 & 255 & 150 & 388 \\
\hline Stroke & 69 & 168 & 99 & 218 & 138 & 329 \\
\hline
\end{tabular}

are considered necessary by family doctors and patients, the heavier work burden and lower service reimbursement have limited their numbers. It is therefore essential to define reasonable service lists and improve pay to increase the number of family (home) care beds. ${ }^{11}$

Home visits are considered a useful basic clinical service for

the less-educated doctors and nurses in CHS organizations, especially station staff. First, the central government established favorable policies for CHS workers, for example, by raising salaries and subsidies and shortening tenure periods for promotion to higher professional titles, in an attempt to attract experienced doctors and nurses to take jobs in CHS organizations. ${ }^{9}$ Second, some specialists from tertiary hospitals are encouraged to take on part-time work in CHS organizations. Third, the government provides on-the-job training programs, degree advancement education programs, and practical skills training programs for CHS doctors and nurses, and it gives them more financial support to finish these programs. ${ }^{6}$

Such on-the-job training programs, which provide opportunities for trainees to improve their skills and obtain a higher professional title, will result in the retraining of most of the less-educated professionals currently working in CHS organizations and allow them to become eligible family (general) doctors in accordance with the national training standards. Incentives of $¥ 1500$ and $¥ 900$ will be paid for 1 family doctor and 1 nurse to complete 300 and 200 study hours, respectively. ${ }^{7}$ Meanwhile, costs for this program will be audited by provincial health administration departments. ${ }^{10}$

\section{Service Functions in CHS Organizations}

CHS organizations provide basic clinical and public health services. Basic clinical services consist of diagnosis and treatment of common diseases, traditional Chinese medicine, emergency care, family (home) care beds, home visits, and referral services. Public health services include management of noncommunicable chronic diseases, maternal and child care, elderly care, resident health record management, health care contracting, physical rehabilitation, planned immunizations, and health education. ${ }^{7}$

The number of family (home) care beds and home visits is increasing gradually. Family (home) care beds are convenient for the family and allow the doctor to visit patients at home so that patients receive better medical care. Although the family (home) care beds
CHS. Home visits can be used to assess discharged patients and to manage patients with noncommunicable chronic diseases in the home. ${ }^{12}$ Currently the home care team, which includes a family doctor, a nurse, and preventive medical staff, is responsible to implement this task in each CHS organization. The rules relating to home visits and their funding are still in the process of being upgraded.

The 2004 survey results showed that operating hours were shorter in stations than in CHS centers. For most residents, the stations are closer to their homes, and thus the doctors or nurses are more accessible and visiting them is more convenient. ${ }^{13,14}$ The residents hope that stations will increase their open hours, especially for emergency and night services. The central government is considering enriching medical staff in stations and giving more subsidies to help stations prolong their hours of operation. ${ }^{15-17}$

Public health services are a primary component of CHS. The core tenets of public welfare are embodied in these services. Care for children includes establishing children's health records and vaccinating children aged 0 to 6 years, regular well-child periodic visits, and supervision of their care. Maternal care includes periodic health examinations, health education, and birth defect monitoring. Through maternal care, the health status of pregnant woman can be effectively supported, and fetal development can be followed medically. Maternal care plays an important role in reducing the mortality and morbidity of pregnant women and neonates.

An accurate and organized health record is important to CHS: (1) doctors record their diagnosis and treatment strategies in the health record; $(2)$ the health record embodies the essential principles of availability of information, which contributes to the continuity of general practice and reflects the biopsychosocial medical model $;$ (3) the health record is the legal record for $\mathrm{CHS}_{\text {; }}$ and (4) the health record becomes a tool for the assessment of the quality of CHS care. $^{18}$

In China, the overall disease profile now resembles that of a developed country, with more than $78 \%$ of deaths caused by noncommunicable chronic diseases 
in $2003 .{ }^{20}$ It is important for medical staff to prevent and treat noncommunicable chronic diseases effectively, and the Chinese government believes improving the management of noncommunicable chronic diseases in CHS centers and stations is essential. The following steps are being undertaken to facilitate chronic disease management: (1) establishing a CHS information system in many provinces that includes a patient registry and reminder system $m_{i}(2)$ emphasizing the role of work teams in the management of noncommunicable chronic diseases; and (3) developing clinical guidelines for treating noncommunicable chronic diseases.

Health education is considered an important way for enhancing health and of helping people access health care. ${ }^{19}$ There are 2 main methods of health education used in CHS organizations in China. One is public health education for all residents, in which visual health educational materials, health leaflets, videodiscs, and health classes are used. The other is education for patients, called personal education, which helps patients to acquire medical knowledge of self-care techniques. Because the population with health problems usually want to get more information, this personal education can be conducted easily by family doctors and is actively welcomed by patients.

There has not been any follow-up since the initial national CHS survey in 2003. Another national survey is needed to update these data so we can generate more feedback for experience-based suggestions and can apply theoretical analysis for improving the Chinese CHS.

To read or post commentaries in response to this article, see it online at http://www.annfammed.org/cgi/content/full/6/5/421.

Key words: Community health services; health manpower; delivery of health care; China

Submitted October 11, 2007; submitted, revised, March 18, 2008; accepted March 27, 2008.

Funding support: The research was financially supported by the Ministry of Health of the People's Republic of China.

Acknowledgments: We are grateful to staff from the Ministry of Health of the People's Republic of China for support and technical advice; to Liqun Liu for his help in designing the survey; to Jing Guan for her help in fielding the survey; to Yuxiang Yan for her help in organizing and analyzing the data; and to Kurt C. Stange, Xijuan Fu, Wei Wu, and Shige Song for helpful comments on an earlier version of the paper. We also appreciate O. Daniel Smith, MD, family physician for his editorial assistance.

\section{References}

1. Wang J, Kushner K, Frey JJ III, MD, Du XP, Qian N. Primary care reform in the Peoples' Republic of China: implications for training family physicians for the world's largest country. Fam Med. 2007;39(9):639-643.

2. Blumenthal D, Hsiao W. Privatization and its discontents-the evolving Chinese health care system. N Engl J Med. 2005;353(11):1165-1170.

3. Nieman LZ, James Kvale, Xijuan Fu, Yuan Gu, Strobel HW. Bringing a family practice model of health to the People's Republic of China. Fam Med. 2001;33(9):696-701.

4. Mitsuhashi K. Evolution of village doctors from the communist regime to contemporary China: reeducation of the "barefoot doctors" in rural communities. Nippon Ishigaku Zasshi. 2005;51(4):569-592.

5. Wang $H, X u T, X u J$ J. Factors contributing to high costs and inequality in China's health care system. JAMA. 2007;298(16):1928-1930.

6. Liang W. General Practice [in Chinese]. Beijing: Higher Education Press; 2004.

7. PR China State Council. Improving the community health service in China. Policy statement. Documents issued by State Council. Available at: http://www.moh.gov.cn/publicfiles/business/htmlfiles/ mohfybjysqwss/pztq/list.htm.

8. Wang Y, Guan J, Li J, Liang W. Actuality of inhabitant's satisfaction about service in medical institutions [in Chinese]. Chinese Gen Pract. 2006;9(13):1050-1053.

9. Yang $X$, Yang J, Wang Y, Liang W. Result analysis of the focus group discussion about CHSs in Beijing [in Chinese]. Chinese Gen Pract. 2006;9(15):1264-1266.

10. Wang Y, Li H, Liu L, Yan Y, Liang W. An investigation of the establishment and implement status of different level governmental measures of CHS [in Chinese]. Chinese Gen Pract. 2005;8(11):869-872.

11. Wang C, Liang W, Wang Y, Li Y. Investigation of attitude towards family care bed by family doctor and nurse in China [in Chinese]. Chinese Gen Pract. 2005;8(11):942-944.

12. Mcwhinney IR. An Introduction to Family Medicine. New York, NY: Oxford University Press; 1981.

13. Fang Y, Guo A, Li J, Liang W. An investigation of Chinese CHS - an analysis and survey on the present situation of central management and health service of CHS Centers of eastern, western and middle China [in Chinese]. Chinese Gen Pract. 2005;8(17):1389-1392.

14. Liang W, Wang Y, Li H. Comparative analysis of accessibility of the hospital service and CHS [in Chinese]. Chinese Gen Pract. 2006;9(11):908-910.

15. Liang W, Li C, Yang X, Guan J, Guo A. A survey on the present situation of Chinese CHS-a comparison among the service forms of CHS Organizations in the eastern, middle and western areas [in Chinese]. Chinese Gen Pract. 2005;8(21):1739-1740.

16. Gao H, Wang Y, Li C, Liang W. Analysis on the income and expense of the CHS Centers in China from 2000 to 2002 [in Chinese]. Chinese Gen Pract. 2006;9(5):356-358.

17. Liang W, Gu J, Wang H, Li C. Analysis of the income and expense of CHS Institutions in 2000-2002 [in Chinese]. Chinese Gen Pract. 2006;9(9):698-699.

18. Gu Y. The Introduction of General Practice [in Chinese]. Beijing: People's Medical Publishing House; 2001.

19. United Nations Health Partners Group in China. A Health Situation Assessment of the People's Republic of China. Beijing: World Health Organization; 2005.

20. PR China state council. Chinaview about China: names of provinces, autonomous regions and municipalities for details. China View. 2000. http://news.xinhuanet.com/english/2003-02/19/content_815536.htm. 